\title{
Prevalence of Obesity in Elementary Schools in Mardin, South-Eastern of Turkey: A Preliminary Study
}

\author{
Betül Battaloğlu İnanç', Deniz Say Şahin'1, Ayşe Ferdane Oğuzöncül' ${ }^{2}$ Recep Bindak ${ }^{3}$, Feride Mungan' \\ ${ }^{1}$ Health Higher School, Mardin Artuklu University, Mardin, Turkey \\ ${ }^{2}$ Department of Public Health, Faculty of Medicine, Fırat University, Elazığ, Turkey \\ ${ }^{3}$ Department of Statistics, Mardin Artuklu University, Mardin, Turkey
}

\begin{abstract}
Objective: This research determines the frequency of obesity among primary school-aged children and evaluates the relationship between obesity and family and environmental factors.

Material and Methods: Three thousand four hundred sixty students, aged 6-15 years in three primary schools in Mardin city center were taken into the study. Information about eating habits and family-environmental factors were obtained by questionnaire. For each student we calculated the body mass index (BMI) and the $\geq 97$ percentile was defined as obese, and between $85-97^{\text {th }}$ percentile as overweight. These values were calculated with the SPSS statistical program. Chi-square and t-tests were used for analysis. $p<0.05$ was considered statistically significant.

Results: $48.2 \%$ of the students were female. In the assessment of body mass index (BMI) the overweight rate for children was $15.78 \%$, the obese rate was $10.57 \%$. The prevalence of obesity according to gender was $9.05 \%$ for girls and $11.97 \%$ for boys $(p<0.01)$. The mean BMI of the girls in the age group 13-15 is higher than in males of the same age. Those in the higher socio-economic group had a higher prevalence of obesity ( $<<0.01)$. Paternal obesity affected child obesity $(p<0.01)$. Children who eat irregular meals $(p=0.05)$, watch more than 2 hours per day TV $(p=0.03)$, were breastfed for less than 6 months $(p<0.05)$ and the mothers' obesity $(p<0.05)$ were found to have a significantly higher prevalence of obesity.

Conclusion: Obesity is increasing throughout the world as a health problem. Being obese in childhood and having obese parent(s) are two of the risk factors of being obese in adulthood. Persistence of obesity into adulthood is the most serious aspect of the problem. The therapeutic success rate in obesity is unfortunately not high. Therefore, a preventive strategy involving early identification of those at risk by incorporating body mass assessments to routine childhood growth assessment appears to be the most prudent strategy.
\end{abstract}

Key Words: Childhood obesity, prevalence, body mass index, Mardin, Turkey

Received: 13.03.2012

Accepted: 14.06 .2012

\section{Introduction}

Obesity and overweight are defined by the World Health Organization (WHO) as 'abnormal or excessive fat accumulation that may impair health' (1). The problem of excessive weight and obesity is increasing world-wide. According to the $\mathrm{WHO}$, there are over 1.6 billion overweight and 400 million obese people in the world, these figures are expected to reach 2.3 billion and 700 million respectively in 2015 (2). Childhood obesity has increased dramatically over the last decade. In 2010, the number of overweight children under 5 years old was estimated to be around 43 million, with 35 million of these children living in developing countries (3). $90 \%$ of those who are obese in adolescence become obese adults; $75 \%$ of 12 -year-olds who are obese go on to become obese adults; $41 \%$ of 7 -year-olds who are obese become obese in adulthood; $25 \%$ of those obese in the pre-school period become obese adults, and $14 \%$ of those obese at infancy are at risk of being obese adults (4). The presence of childhood obesity increases the risk of non-communicable diseases such as metabolic syndrome, type 2 diabetes, hypertension, hy- perlipidemia, cardiovascular disease and certain cancers (colon, breast, gall bladder, endometrium) $(5,6)$. Furthermore the level of depression in obese children is determined to be significantly higher than in non-obese children (7). Both the child's nutritional intake and eating habits are shaped in infancy, notably by the parents' diet and family characteristics (8). A marked difference between the sexes in the prevalence of obesity is noted, it tends to be more prevalent in males during early childhood and more frequent in adolescence girls (9). Obesity is a product of a variety of social, behavioral, cultural, environmental, physiological and genetic factors (8).

\section{Material and Methods}

This is a community-based cross-sectional study. There were 4030 attendant students in three schools. 3460 (1667 female, 1793 male) volunteer children in the 6-15 years age group were surveyed for the study, which was carried out in the city center of Mardin in the south-eastern region of Turkey. The population of the Mardin province is around 
745000 , and the population of the city of Mardin is approximately 90000 . The number of children and young adults aged 6-17 years is $31 \%$ of the total population. There were nineteen elementary schools, and three schools were selected randomly on the basis of three different socio-economic levels. However, the children were not asked about the family income level. The target population was 27000 children. We have used a random cluster sampling method. The sample size formula is based on the known number of individuals in the population, and according to the literature, the estimated prevalence of obesity is $20 \%$. A $2 \%$ error rate was allowed and the degree of confidence was calculated as $95 \%$. Thus the minimum sample size was calculated as 2205 . The data was collected in April and May of 2011. After consultation with school management, all measurements were taken with their summer uniforms (only coat without jacket) and without shoes. Weight was measured to the nearest $0.1 \mathrm{~kg}$ using an electronic column scale; height was measured to the nearest $0.1 \mathrm{~cm}$ using a flexible tape with the head in the Frankfort horizontal plane. Students completed a questionnaire which was designed by the researchers. Students answered questions on demographic characteristics, eating habits (at home and in school) and physical activities. Physical activities were separated into two groups; organised sports (athletics, judokarate, table tennis, etc) and non-organised sports (football, basketball, rope jumping). Questionnaire forms were sent to all of the families and each family was also sent a questionnaire to fill in which asked about the size and weight of parents, birth weights of children $(n=888 ; 26 \%)$ and breastfeeding duration ( $n=1499 ; 43 \%)$. Parents' height and weight were obtained by self-completed questionnaire (1459 mothers $42 \%$ and 1426 fathers $41 \%$ values). Parents' and children's BMI were calculated by dividing weight in kilograms by height in square metres. Calculated BMI for all parents were determined by WHO classifications (10). Obesity is described as $\geq 30 \mathrm{BMI}$ for adults. According to the WHO report published in 2007, growth reference values for children and adolescents in the 5-19 years of age group were calculated on the basis of the BMI value of (11). A BMI value exceeds $97^{\text {th }}$ percentile on the children who are obese, a BMI value between $85-97^{\text {th }}$ percentile for overweight was defined. Ethical approval was given from Mardin Artuklu University and Mardin Educational and Health Directorate Office.

\section{Statistical analysis}

Collected data was coded and digitized. Statistical analysis was performed with SPSS statistical software and Microsoft Office Excel. According to the WHO reference values, obese and non-obese children and their parents' data were evaluated by chi-square test for categorical variables, and metric measurement variables were compared by independent samples t-test. Statistical significance level was set at 0.05 .

\section{Results}

$48.2 \%$ of the students were female and $51.8 \%$ of them were male. The average age of students was $10.7 \pm 2.1$ years, their mean height was $141.4 \pm 14.5 \mathrm{~cm}$, their mean weight was $37.6 \pm 13.2 \mathrm{~kg}$ and their mean $\mathrm{BMl}$ was $18.27 \pm 3.53$. In the assessment of $\mathrm{BMI}$, the overweight rate of children was $15.78 \%(n=546)$, obese rate of children was $10.57 \%(n=366)$ and $26.35 \%$ of children were identified as overweight to varying degrees. The prevalence of obesity according to gender was found to be $9.05 \%(n=151)$ for girls and $11.97 \%(n=215)$ for boys. The prevalence of obesity was significantly higher in males $\left(\chi^{2}=9.813 ; p<0.001\right)$ (Table 1$)$.

It was noted that the prevalence of obesity in both males and females in the 13-15 years age group increased. If the BMI mean values are compared according to gender, the 7-9 years old male students were higher than the mean value $(t=2.116$; $p<0.05)$; whereas the female students in the 13-15 years age $(t=3.279 ; p<0.01)$ were found significantly higher than the mean BMI values (Table 2). The prevalence of obesity (12.6\%) among students going to a school that represents the upper socio-economic levels was found to be significantly higher than others $\left(\chi^{2}=11.268 ; p<0.05\right)$ (Table 3$)$. The prevalence of obesity was lower among those having regular 3 meals a day than among those eating irregularly $(1,2,4$ or 5 times $)\left(\chi^{2}=3.627 ; p=0.057\right)$. The children who participated in our study were spending an average of 2.40 hours watching TV and 1.38 hours on the computer. When children were divided into two categories, the prevalence of obesity in those watching TV for $0-2$ hours was 9.8\%; in those watching over 2 hours TV it was $12.3 \%$. The relation was statistically significant $\left(\chi^{2}=4.916 ; p=0.03\right)$. In our study, the prevalence of obesity of 0-2 hour's computer users was $11.7 \%$; over 2 hours computer users was $11.5 \%$. The relation was not statistically significant ( $p>0.05)$ (Table 4).

Table 1. Percentile values of BMI according to gender and age group

\begin{tabular}{|c|c|c|c|c|c|c|c|c|c|c|c|}
\hline \multirow[b]{2}{*}{ Age } & \multirow[b]{2}{*}{ Gender } & \multicolumn{2}{|c|}{$<.03$} & \multicolumn{2}{|c|}{$.03-.15$} & \multicolumn{2}{|c|}{$.15-.85$} & \multicolumn{2}{|c|}{$.85-.97$} & \multicolumn{2}{|c|}{$>.97$} \\
\hline & & $n$ & $\%$ & $n$ & $\%$ & $\mathrm{n}$ & $\%$ & $n$ & $\%$ & $\mathrm{n}$ & $\%$ \\
\hline \multirow[t]{2}{*}{$7-9$} & Girl & 14 & 2.6 & 63 & 11.8 & 338 & 63.5 & 82 & 15.4 & 35 & 6.6 \\
\hline & Boy & 13 & 2.4 & 53 & 9.6 & 355 & 64.2 & 69 & 12.5 & 63 & 11.4 \\
\hline \multirow[t]{2}{*}{$10-12$} & Girl & 25 & 3.5 & 94 & 13.3 & 414 & 58.6 & 105 & 14.9 & 69 & 9.8 \\
\hline & Boy & 19 & 2.5 & 69 & 8.9 & 478 & 61.8 & 113 & 14.6 & 94 & 12.2 \\
\hline \multirow[t]{2}{*}{ 13-15 } & Girl & 15 & 3.5 & 42 & 9.8 & 238 & 55.6 & 86 & 20.1 & 47 & 11.0 \\
\hline & Boy & 15 & 3.2 & 56 & 11.9 & 249 & 53.1 & 91 & 19.4 & 58 & 12.4 \\
\hline \multirow[t]{2}{*}{ Total } & Girl & 54 & 3.2 & 199 & 11.9 & 990 & 59.4 & 273 & 16.4 & 151 & 9.1 \\
\hline & Boy & 47 & 2.6 & 178 & 99 & 1082 & 60.3 & 273 & 15.2 & 215 & 12.0 \\
\hline
\end{tabular}


The incidence of obesity among students going to school by service bus was higher than the ones walking to school. However, the difference was not statistically significant. In this study, the rate of those not involved in sports seems to be $57.8 \%$. 3.4\% of children were involved in amateur sports. All the children were exercising on average 1.34 days per week and 32.4 minutes per day. The average exercise time of obese group and non-obese group was similar. Although the

Table 2. Comparison of the mean values of BMI according to age groups of the students by gender

\begin{tabular}{|c|c|c|c|c|c|c|}
\hline $\begin{array}{l}\text { Age } \\
\text { Group }\end{array}$ & Gender & $\mathrm{n}$ & $\begin{array}{c}\text { Mean } \pm \\
\text { Standard } \\
\text { Deviation }\end{array}$ & $t$ value & $\begin{array}{c}\text { Obesity } \\
\text { Rate }\end{array}$ & $p$ \\
\hline \multirow{2}{*}{$\begin{array}{l}7-9 \\
\text { Age }\end{array}$} & Girl & 532 & $16.36 \pm 2.37$ & \multirow{2}{*}{$2.116^{\star}$} & 6.58 & \multirow[t]{2}{*}{$0.034^{\star}$} \\
\hline & Boy & 553 & $16.68 \pm 2.50$ & & 11.39 & \\
\hline \multirow{2}{*}{$\begin{array}{l}10-12 \\
\text { Age }\end{array}$} & Girl & 707 & $18.21 \pm 3.27$ & \multirow{2}{*}{0.194} & 9.76 & \multirow[t]{2}{*}{0.846} \\
\hline & Boy & 773 & $18.25 \pm 3.15$ & & 12.16 & \\
\hline \multirow{2}{*}{$\begin{array}{l}13-15 \\
\text { Age }\end{array}$} & Girl & 428 & $20.91 \pm 4.03$ & \multirow{2}{*}{$3.279 *$} & 10.98 & \multirow[t]{2}{*}{$0.001 *$} \\
\hline & Boy & 469 & $20.05 \pm 3.77$ & & 12.36 & \\
\hline
\end{tabular}

incidence rate of obesity in non-organised sport players was higher than organised sport players, no statistically significant relationship was found $\left(\chi^{2}=1.777 ; p>0.05\right)$ (Table 4$)$.

Children participating in the study were formed into two categories according to their duration of breast-feeding, "up to 6 months" and "7 months and over", and the incidence of obesity was compared within these two groups. Categorical analysis of 1499 children's duration of breast feeding data shows that duration of breast feeding is statistically significant $\left(\chi^{2}=5.419 ; p<0.05\right)$ and the longer the period the less

Table 3. Comparison obesity with socio-economic level

\begin{tabular}{|lcccccc|}
\hline & $<.03$ & $.03-.15$ & $.15-.85$ & $.85-.97$ & $>.97$ & Total \\
\hline Inferior socio- & 42 & 118 & 683 & 160 & 102 & 1105 \\
economic & $3.8 \%$ & $10.7 \%$ & $61.8 \%$ & $14.5 \%$ & $9.2 \%$ & $100.0 \%$ \\
Mild socio- & 26 & 98 & 530 & 156 & 79 & 889 \\
economic & $2.9 \%$ & $11.0 \%$ & $59.6 \%$ & $17.5 \%$ & $8.9 \%$ & $100.0 \%$ \\
High socio- & 33 & 161 & 857 & 230 & 185 & 1466 \\
economic & $2.3 \%$ & $11.0 \%$ & $58.5 \%$ & $15.7 \%$ & $12.6 \%$ & $100.0 \%$ \\
Total & 101 & 377 & 2070 & 546 & 366 & 3460 \\
& $2.9 \%$ & $10.9 \%$ & $59.8 \%$ & $15.8 \%$ & $10.6 \%$ & $100.0 \%$ \\
\hline
\end{tabular}

Table 4. Prevalence of obesity according to some categorical variables

\begin{tabular}{|c|c|c|c|c|c|c|}
\hline & Category & $\mathrm{n}$ & Non obez & Obez & $\chi^{2}$ & $\mathrm{p}$ \\
\hline \multirow[t]{2}{*}{ Gender } & Girl & 1667 & 1516 & 366 & $9.813^{\star \star}$ & $0.001^{\star \star}$ \\
\hline & Boy & 1793 & 1578 & 215 & & \\
\hline Socio-economic & Lower & 1105 & $90.8 \%$ & $9.2 \%$ & & \\
\hline \multirow[t]{2}{*}{ Status } & Medium & 889 & $91.1 \%$ & $8.9 \%$ & $11.268^{\star \star}$ & $0.003^{\star \star}$ \\
\hline & High & 1466 & $87.4 \%$ & $12.6 \%$ & & \\
\hline \multirow[t]{2}{*}{ Number of Meals } & Three Times & 2240 & $90.2 \%$ & $9.8 \%$ & & 0.056 \\
\hline & Various & 1218 & $88.1 \%$ & $11.9 \%$ & 3.627 & \\
\hline \multirow[t]{2}{*}{ TV } & $0-2$ hours & 2188 & $90.2 \%$ & $9.8 \%$ & & $0.0266^{*}$ \\
\hline & 3 hours and over & 1170 & $87.7 \%$ & $12.3 \%$ & $4.916^{*}$ & \\
\hline \multirow[t]{2}{*}{ Computer } & 0-2 hours & 2052 & $88.3 \%$ & $11.7 \%$ & & 0.9203 \\
\hline & 3 hours and over & 313 & $88.5 \%$ & $11.5 \%$ & 0.010 & \\
\hline \multirow[t]{2}{*}{ Coming to School } & With service bus & 1407 & $88.5 \%$ & $11.5 \%$ & & 0.2195 \\
\hline & walking & 1973 & $89.8 \%$ & $10.2 \%$ & 1.507 & \\
\hline \multirow[t]{3}{*}{ Sport } & Non-participant & 2006 & $90 \%$ & $10 \%$ & & \\
\hline & Organized & 1117 & $88.5 \%$ & $11.5 \%$ & 1.777 & 0.1824 \\
\hline & Non Organized & 337 & $89.3 \%$ & $10.7 \%$ & & \\
\hline Breast Feading & 0 - 6 months & 552 & $88.2 \%$ & $11.8 \%$ & & $0.0201^{*}$ \\
\hline Time & 7 months and over & 947 & $91.8 \%$ & $8.2 \%$ & $5.401^{*}$ & \\
\hline \multirow[t]{2}{*}{ Maternal Obesity } & Normal & 1243 & $91.3 \%$ & $8.7 \%$ & & $0.0238^{*}$ \\
\hline & Mother Obese & 216 & $86.6 \%$ & $13.4 \%$ & $5.106^{*}$ & \\
\hline \multirow[t]{2}{*}{ Paternal Obesity } & Normal & 1209 & $91.8 \%$ & $8.2 \%$ & & $0.0014^{\star *}$ \\
\hline & Father Obese & 217 & $84.8 \%$ & $15.2 \%$ & $10.153^{\star \star}$ & \\
\hline \multirow{2}{*}{ Fastfood Consumption } & Never eat & 1965 & $90.1 \%$ & $9.9 \%$ & & 0.1220 \\
\hline & At least once a week & 1495 & $88.5 \%$ & $11.5 \%$ & 2.391 & \\
\hline
\end{tabular}


the prevalence of obesity. The average duration of breast feeding $(12.13 \pm 9.34$ month) of the children defined as obese was lower than the average (13.14 \pm 8.12 month) of the nonobese ones. No significance was found in the difference found in terms of the average duration of breast feeding $(t=1.389$; $p>0.05)$. The average birth weight of children was calculated as $3206 \pm 476 \mathrm{gr}$. The average birth weight of the children defined as obese was higher than the non obese children; however, the difference was not statistically significant.

The average BMI for 1459 mothers was $26.11 \pm 3.79$ and for 1426 fathers $\bar{X}=26.66 \pm 3.3714 .8 \%$ of mothers and $15.2 \%$ of fathers were obese. There was a significant relationship between obese parents and obese children. Child obesity was found significant in relationships between mother and daughter $\left(\chi^{2}=4.246 ; p<0.05\right)$ and father and son $\left(\chi^{2}=8.560 ; p<0.05\right)$. In addition, according to the data taken from the 1413 children with information about parents, the obesity rate of those with just one obese parent was $11.6 \%$, while for those with both parents obese, the rate was $21.3 \%$. One other interesting result, the percentage of parents who answered 'yes' to the question "is there any obese person in the family" was just $9.4 \%$. Table 5 shows the distribution of food-types which students buy from the canteen. $66.7 \%$ of food buyers take bagels-savoury pastry whereas $24.2 \%$ buy biscuit-crackers. $21.4 \%$ fruit juice and $17.4 \%$ carbonated soft drinks were taken as beverages. On the other hand, it is important to note that the rate of those that could be defined as having a healthy diet was very low, for instance the milk drinker's rate was $3.12 \%$ and the rate of the ones fed with the food prepared by the mother was only $1.42 \%$. An interesting finding from the responses was that, although the brand of the products were not asked, $50 \%$ of students who ate biscuits, $17 \%$ of those who consumed sweets and $98 \%$ of those who consumed carbonated drinks responded by giving the brand name of the product. This shows that ads have a considerable role in food consumption. In addition, the percentage of children who consumed fast food such as fried potatoes, pizza, and hamburger at least once a week was $42.1 \%$ while $56.8 \%$ of the students $(n=1965)$ did not eat fast food at all. The incidence of obesity

Table 5. Types of food which children bought from the school canteen or school environment

\begin{tabular}{|lcc|}
\hline Nutrition & Frequency & Percent \% \\
\hline Biscuit & 839 & 24.25 \\
Toast, bagels, pastry & 2308 & 66.71 \\
Confectionery & 79 & 2.28 \\
Carbonated Drink & 602 & 17.40 \\
Fruit juice & 741 & 21.42 \\
Buttermilk & 221 & 6.39 \\
Milk & 108 & 3.12 \\
Fruit & 724 & 20.92 \\
Cake, Pie, Cookies & 422 & 12.20 \\
Chocolate & 588 & 16.9 \\
Welfare meals brought from home & 49 & 1.42 \\
\hline
\end{tabular}

in children who consumed fast food at least once a week was higher, but this was not statistically significant (Table 4).

\section{Discussion}

According to research, $90 \%$ of those who were obese in the adolescent period and $75 \%$ of those who were obese at the age of 12 , remain obese when they reach adulthood (4) This shows how important obesity can be in childhood and adolescence as a health issue. It is found that the countries of Europe in which the prevalence of overweight was higher in school-age children are Spain (35\% in 6-9 ages) and Portugal (32\% in 7-9 ages); the countries with the lowest rates are Slovakia (15\% in 6-9 ages), France (18\% in 7-9 ages), Switzerland (18\% in 6-9 ages) and Iceland (18\% in 9 age) (12).

According to the HBSC survey carried out in Turkey in 2001-2002, in the 11 years age group 7\% of females and $14 \%$ of males were found to be overweight or obese, in the 13 years age group $7 \%$ of females and $13 \%$ of males, and in the 15 years age group $5 \%$ of females and $14 \%$ of males (13). Although there is no study covering Turkey as a whole, there are studies made in various provinces and reporting local prevalence. In Ankara the prevalence of 6-17 years age group of 1510 children was found to be $4.8 \%$ (14). The prevalence of obesity found in Samsun among 4120 children was $7.3 \%$ in females and 4\% in males (15); in Bursa among 5795 children $1.5 \%$ in females and $1.8 \%$ in males $(16)$; in Mardin among 715 children $4.4 \%$ in females and $4.3 \%$ in males (17); in Denizli the average for males and females was $1.4 \%$ from 850 children (18); in Muğla among 1179 children living in rural areas was $6.6 \%$ in females and $7.6 \%$ in males (19); in Istanbul, Ankara and Izmir among a total of 1044 children the average for males and females was $2 \%$ (20). The average obtained of $10.57 \%$ in our study is higher than the results of other studies which took place in Turkey. This result suggests the idea that it could be dependent on regional eating habits, highcarbohydrate and meat consumption, lack of social and physical activity areas. In addition, the fact that obesity is higher in male children than in female also suggests the idea that male children are seen as more precious and special so it could be dependent on the relaxed lifestyle that is presented to them. $\mathrm{BMI}$ mean values were determined to be significantly higher in 7-9 year old males and 13-15 year old females. The phenomenon of obesity encountered was higher in females than males in the primary school age and the stages of puberty (21). While in prepuberty an increase in the incidence of obesity is observed in both males and females, during the beginning of menstruation a substantial proportion of excess weight is seen in girls, and it is known that with the progression of puberty a reduction in adipose tissue of the male child appears (22). The findings of our study also support this. On the obesity of 1315 year old females, besides the onset of puberty, it can also be dependent on parents refusing to let them go out to play with other girls, thus this places a restriction on possible activities. Although, according to the literature, the prevalence is higher in the children of socioeconomically poor families of developed countries, the prevalence of obesity is greater in the families with higher economic levels in developing coun- 
tries (23). Taking into consideration that Turkey is a developing country, in our study the significant discovery of higher prevalence of obesity in the high socioeconomic group seems to be in parallel with the situation.

Having a snack is a common problem in school-aged children. According to the findings of our study, the prevalence of obesity was found to be less for individuals who get main meals regularly and three times a day than for ones who take their meals irregularly (1, 2, 4 or 5). In a study by Elgar et al. (24), it was determined that people of normal weight skipped breakfast once a week, whereas obese adolescents skipped breakfast twice a week. There was a significant correlation between the time spent in front of the TV of the children participating in the study and obesity. In some scientific studies that have been carried out, a significant relation between the time in front of the TV and prevalence of obesity has been found $(25,26)$. The American Academy of Pediatrics, as a preventive measure for childhood obesity, recommends eating food at home with the TV off and to limit the time of TV-video games as a max. 2 hours in a day (27). In the light of this information, importance increases as to whether snacks are taken during the time in front of the TV and the determination of whether the fascinating effect of TV on people blunts awareness of eating quantities. Although the rate of obesity between those using the school bus is higher than for the children going on foot to and from school, the difference was not statistically significant. It is possible to come across studies supporting this finding (28). In this study, an insignificant difference between the rate of coming and going by school bus and on foot to school was found. It is assumed that because the city in which the study was carried out is relatively small and so the children come and go to school by foot due to the short distance. In a study involving thirty-four countries and 137593 school children, it was concluded that regular physical activity significantly reduces overweight when compared with those of normal weight, obese adolescents do less physical activity and watch TV much more. Obesity treatment guidelines in the U.S.A., Canada, and Great Britain recommend young people to do physical activity at least 30-60 minutes of most days in a week (29). The children in this study have done sport on average 1.34 days a week and 32.4 minutes a day. However, obese group and normal groups were similar in terms of average time doing sports. Although the rate of obesity amongst the children who play in the street is more than those doing organised sports, there was no statistically significant relation. This result can be connected with the smaller number of those doing unorganised sports and obese children who do more activities wanting to lose weight. The energy of the schoolage children should be expended by means of physical activity, organizations for sports activities should be planned, and the continuity of sports throughout life should be provided.

Diet in the first years of life impacts on growth, development and obesity. Although the extent to which the effect of breast milk on obesity has not been proved definitely, according to the meta-analysis studies, it is considered that breast milk reduces the risk of obesity by $10-20 \%$ (30). Duration of breastfeeding affects obesity inversely. It is reported that childhood obesity is less in children who were breastfed than in those not breastfed (31); breastfeeding for a month reduces the risk of obesity in children by $4 \%$ (32).

In a study on the duration of breast feeding and obesity development, the frequency of overweight of those breast fed for over 11 months was found to be lower than those breastfed for less than 3 months (33). According to data from the Turkish Ministry of Health in 2010, 27.4\% of the women in Turkey are overweight and $18.5 \%$ obese; $36.9 \%$ of men are overweight and $12.3 \%$ of them are obese (34). $14.8 \%$ of mothers of the children and $15.2 \%$ of fathers of children in our study were found to be obese. Obesity in the family is one of the most important risk factors for childhood obesity (8). Familychild relationship influences the child both genetically and environmentally. According to research, if both the parents are overweight, the risk of obesity for their children is $80 \%$; if one of the parents is obese, the risk is $40 \%$ and if both parents are of normal weight, the risk is $14 \%$ (35). In this study, there was a significant relationship between obese parents and obese children. In addition, in the comparison of children according to their genders, a significant relationship was found between the obesity of mother and daughter and between the obesity of father and son. This result supports the idea that parents are role models in the selection of diet type and in the development of their children. The necessity of the awareness of parents about obesity and the changing of the accepted image of obesity due to the social cases has been remarked. In addition, children should be trained in school for the prevention of obesity and the importance of the information and raising awareness activities for parents emerges.

In recent years in Turkey, especially in urban areas, fastfood consumption among children and adolescents is often seen to be the preferred nutrition form. Fast food is nutritious, its content of saturated fatty acids and salt is rich, but it is inadequate from the point of its content of sediment, $A$ and $C$ vitamins, and calcium; commonly such nutrition causes malnutrition; it increases the risk of chronic diseases such as obesity, cardiovascular disease, and diabetes. The province of Mardin has newly met with fast food consumption and accordingly we think that the frequency of consumption has been lower due to the fact that the sales points have not been widespread yet. According to research in West Harlem, New York, America, the $\mathrm{BMI}$ percentiles of children living in the places where they can go easily to the shops (such as fast food, grocery and markets) are proved to be significantly higher than the those living in places where there was no such shop (36). There is a strong positive connection between the consumption of fast food and gaining weight and insulin resistance. In the study of CARDIA, 3031 young adults were followed progressively for 15 years; it was determined that participants eating fast food in excess of two times per week put on an extra $4.5 \mathrm{~kg}$ weight and experience an increase of insulin resistance in excess of twice those who eat fast food at least once in a week (37). In addition to fast food, childhood obesity is increasing in parallel with the rapid increase in consumption of sugared drinks, and it is stated that educational and political measures need to be taken (38). The WHO stated that calories from free sugar should not exceed $10 \%$ of the daily needs (39). In the consumption of liquid, it is recommended that milk and pure (100\%) fruit juice as a water 
source is preferred because they contain substantial nutrients such as calcium and vitamin C (40). However, in another study in Turkey, the conclusion was reached that milk was consumed less than any other drink in all student groups, just as in our study (41).

\section{Conclusion}

The fact that the obese population is estimated to reach 700 million by 2015 imposes different responsibilities on individuals in order to prevent obesity, one of the biggest health problems of our age. Continuing the habit of consuming home-cooked food in our city seems to have survived better with the spreading of fast food, but some changes are necessary in the incidence of food consumption and some forms of consumption. Parental attitudes need to be changed by creating perception and awareness of obesity, and the need for physical activities in daily life should be supported by family education. In fact, accurate and healthy diet, with balanced physical activities, are basic physiological requirements that improve our and our children's living standard.

\section{Acknowledgment}

We would like to sncerely thank all the students and families who participated in this study. No external funding sources were used for this study.

\section{Conflict of Interest}

No conflict of interest was declared by the authors.

\section{References}

1. World Health Organization. Obesity and Overweight. Geneva: World Health Organization; 2012. Available from: http://www. who.int/mediacentre/factsheets/fs311/en (updated 2012 Feb 10).

2. Malik SV, Popkin MB, Bray GA, Despres JP, Hu BF. Sugar-sweetened beverages, obesity, type 2 diabetes mellitus, and cardiovascular disease risk. Circulation 2010;121:1356-64. [CrossRef]

3. De Onis $\mathrm{M}, \mathrm{Blössner} \mathrm{M,} \mathrm{Borghi} \mathrm{E.} \mathrm{Global} \mathrm{prevalence} \mathrm{and} \mathrm{trends}$ of overweight and obesity among preschool children. Am J Clin Nutr 2010;92:1257-64. [CrossRef]

4. Rome SE. Obesity Prevention and Treatment. Pediatr Rev 2011;32:363-73. [CrossRef]

5. World Health Organization. The World Health Report: Reducing risks, promoting healthy life 2002. In: Rodgers A. (editor). Ouantifying Selected Major Risks To Health. 1st ed. France: World Health Organization, 2002.p.47-98.

6. Bianchini $F$, Vainio $H$, Kaaks R. Weight control and physical activity in cancer prevention. Obes Rev 2002;3:5-8. [CrossRef]

7. Dallar Y, Erdeve SS, Cakır I, Kostu M. Does obesity lead to depression and self-esteem deficiency in children? Gulhane Med J 2006;48:1-3.

8. Birch LL, Fisher JO. Development of eating behaviours among children and adolescents. Pediatrics 1998;101:539-49.

9. Oner N, Vatansever U, Sarı A. Prevalence of underweight, overweight and obesity in Turkish adolescents. Swiss Med Wkly 2004;134:529-33.

10. World Health Organization. Global Database on Body Mass Index 2004. Geneva: World Health Organization; 2004. Available from: http://www.who.int/bmi/index.jsp (updated 2012 Feb 15).

11. World Health Organization. Growth reference data for 5-19 years WHO References 2007. Geneva: World Health Organization;
2007. Available from: http://www.who.int/growthref/en/ (updated 2012 Feb 12).

12. World Health Organization/Europe. The challenge of obesity in the WHO European Region and the strategies for response. In: Branca F, Nikogosian H, Lobstein T. (editors). Prevalence and Trends. 1st ed. Denmark: WHO Regional Office for Europe, 2007.p.1-20.

13. World Health Organization/Europe. Inequalities in young people's health. HBSC international report from the 2005/2006 survey. In: Currie C, Gabhainn SC, Godeau E, Roberts C, Smith R, Currie D. et al. (editors). Health Outcomes. Overweight and Obesity. 5th ed. Denmark: WHO Regional Office for Europe, 2008.p.75-8.

14. Simsek F, Ulukol B, Berberoglu M, Gulnar SB, Adıyaman P, Ocal $G$. The prevalence of obesity in a primary school and high school in Ankara. Ankara University Med J 2005;58:163-6.

15. Sancak R, Dündar C, Totan M, Çakır M, Sunter T, Küçüködük $\mathrm{S}$. The Prevalence and the Predisposing Factors of Obesity in Secondary and High School Students. J Exp Clin Med 1999;16:19-24.

16. Akış N, Pala K, Irgıl E, Aydın N, Aksu H. Overweight and Obesity Among 6-14 Year Aged Schoolchildren at Six Elementary Schools in Orhangazi-Bursa. Uludag University Med J 2003;29: 17-20.

17. Gozu A. Prevalence of overweight and obesity among 6-15 year-aged at elementary schools in Mardin. Med Res J 2007;5: 31-5.

18. Semız S, Ozdemır OM, Ozdemir AS. The prevalence of obesity in childhood 6-15 years of age in Denizli. Pamukkkale Med J 2008;1:1-4.

19. Süzek $H$, Arı $Z$, Uyanık $B$. The eating habits and prevalences of overweight and obesity in 6-15 years old school-children living in the villages of Muğla center. The New Journal of Medicine 2010;27:22-8.

20. Sur H, Kolotourou M, Dimitriou M, Kocaoğlu B, Keskin Y, Hayran O, et al. Biochemical and behavioral indices related to $\mathrm{BMI}$ in schoolchildren in urban Turkey. Prev Med 2005;41:614-21. [CrossRef]

21. Peker I, Cıloglu F, Buruk S, Bulca Z. Biochemistry of Exercise and Obesity. 1st ed. Istanbul: Nobel Medical Print, 2000.p.83-97.

22. Gunoz H. Saner G, Demırkol M, Gokcay G, Huner G, Garıbagaoglu M. Nutrition and Nutritional Disorders. In: Olcay Neyzi, Türkan Ertuğrul. (editors). 3rd ed. Istanbul: Nobel Press, 2002.p.221-6.

23. Janssen I, Boyce WF, Simpson K, Pickett W. Influence of individual- and area-level measures of socioeconomic status on obesity, unhealthy eating, and physical inactivity in Canadian adolescents. Am J Clin Nutr 2006;83:139-45.

24. Elgar FJ, Roberts C, Moore L, Tudor-Smith C. Sedentary behaviour, physical activity and weight problems in adolescents in Wales. Public Health 2005;119:518-24. [CrossRef]

25. Dennison BA, Erb TA, Jenkins PL. Television viewing and television in bedroom associated with overweight risk among low-income preschool children. Pediatrics 2002;109:1028-35. [CrossRef]

26. Parlak A, Cetınkaya $S$. The factors that effects constitution of obesity. Journal of Firat Health Services 2007;2:24-35.

27. Krebs NF, Jacobson MS; American Academy of Pediatrics Committee on Nutrition. Prevention of pediatric overweight and obesity. Pediatrics 2003;112:424-30. [CrossRef]

28. Uskun E, Öztürk M, Kişioğlu AN, Kırbıyık S, Demirel R. Risk factor of Influencing the development of obesity in the primary education students. Süleyman Demirel University Med Sci J 2005;12:19-25.

29. Janssen I, Katzmarzyk PT, Boyce WF, Vereecken C, Mulvihill C, Roberts $\mathrm{C}$, et al. Comparison of overweight and obesity prevalence in school-aged youth from 34 countries and their relationships with physical activity and dietary patterns. Obes Rev 2005;6:123-32. [CrossRef] 
30. Savino F, Liguori SA, Fissore MF, Oggero R. Breast milk hormones and their protective effect on obesity. Int J Pediatr Endocrinol 2009:327505. [CrossRef]

31. Arenz S, Rückerl R, Koletzko B, Von Kries R. Breastfeeding and childhood obesity-A systematic review. Int J Obes 2004;28:1247-56. [CrossRef]

32. Harder T, Bergmann R, Kallischnigg G, Plagemann A. Duration of breastfeeding and risk of overweight. A Meta-Analysis. Am J Epidemiol 2005;162:397-403. [CrossRef]

33. Arajua CL, Victora CG, Hallal PC, Gigante DP. Breastfeeding and overweight in childhood: evidence from the Pelotas 1993 birth cohort study. Int J Obes 2006;30:500-6. [CrossRef]

34. The Ministry of Health of Turkey. Health Statistics yearbook. 1st ed. Ankara: Kalkan Press, 2010.p.35-8.

35. Garn SM, Sullivan TV, Hawthorne VM. Fatness and obesity of the parents of obese individuals. Am J Clin Nutr 1989;50:1308-13.

36. Galvez MP, Hong L, Choi E, Liao L, Godbold J, Brenner B. Childhood obesity and neighbourhood food store availability in an Inner city community. Acad Pediatr 2009;9:339-43. [CrossRef]
37. Pereira MA, Kartashov Al, Ebbeling CB, Van Horn L, Slattery ML, Jacobs DR Jr, et al. Fast-food habits, weight gain, and insulin resistance (the CARDIA study): 15-year prospective analysis. Lancet 2005;365:36-42. [CrossRef]

38. Lasater G, Piernas C, Popkin BM. Beverage patterns and trends among school-aged children in the US, 1989-2008. Nutr J 2011;10:103. [CrossRef]

39. Kisioglu NA, Aslan B, Ozturk M. Improving control of high blood pressure among middle-aged Turkish women with low socioeconomic status through public health training. Croatian Med J 2004;45:477-82.

40. Popkin BM, Armstrong LE, Bray GM, Caballero B, Frei B, Willett WC. A new proposed guidance system for beverage consumption in the United States. Am J Clin Nutr 2006;83: 529-42.

41. Yılmaz E, Özkan S. Investigation of nutritional habits in university students. Journal of Firat Health Services 2007;6:87-104. 